\title{
Synthesis, Characterization and Study of Thermally Stable Fluorescent Polyesters
}

\author{
Dilipkumar V. Vasava ${ }^{1, a^{*}}$, Mrs. (Dr) Saurabh K. Patel ${ }^{2, b}$ \\ ${ }^{1}$ Department of Chemistry, Gujarat University, Ahmedabad, Gujarat, India \\ ${ }^{2}$ Department of Chemistry, VNSGU, Surat, Gujarat, India \\ a*dilipvasava20@gmail.com, b saurabhsilvina@gmail.com
}

Keywords: s-Triazine, piperidine, diols, coumarin, viscosity, TGA, fluorescence

\begin{abstract}
Numerous polyesters containing heterocyclic ring have been synthesized by the polycondensation method. Ten Polyesters were synthesised having different aliphatic-aromatic diols in the chain having s-triazine ring as main moiety. The polyesters were synthesized by polycondensation of 6-(N-Piperidinyl)-2,4-bis-(7-Hydroxy-Coumarin-3-carbonyl Chloride)-1,3,5triazine [PCTC] with aliphatic and aromatic diols. Dark brown, light brown, golden and maroon colour showed by novel synthesized polyesters. The solubility of synthesized polyesters was observed in different solvents. The viscosity was studied for all the polyesters. This polyester showed inherent viscosity ranging from $0.402-0.709 \mathrm{dlg}^{-1}$ in $\mathrm{DMF}$ at $25^{\circ} \mathrm{C}$. The synthesized polyesters were characterized by ${ }^{1} \mathrm{H}-\mathrm{NMR}$, FT-IR, fluorescence spectra. Fluorescent polymers are macromolecules with enormous important applications. The measured data indicates the synthesized aliphatic-aromatic fluorescent polyesters, focussing on synthetic methods, properties and applications. Due to their unique mechanical property and workability, their emerging applications involve the fields of fluorescent probe, smart polymer machines, chemo sensors, biological imaging, $\mathrm{P}_{\mathrm{H}}$ /temperature sensor, drug delivery and in many fields. Moreover high quality fluorescent polymers give widespread application in advanced bio imaging, ultrasensitive molecular diagnosis, and novel light emitting nano devices.
\end{abstract}

\section{Introduction}

The polymer chemistry is a multidisciplinary science that deals with the chemical synthesis and chemical properties of polymers. It is emerging as a necessary part of human life and it impacted on the system in which world exists. Amazing variety in the properties of polymeric materials exists [1,2]. Polymers are used in a broad variety of applications [3].A great opportunity is there to become aware of these materials and expand their properties as polymeric material. Growing demands for extremely specialized materials for utilization with specific properties are there in today's scenario. There is massive request for fluorescent polymers for past several decades. Organic fluorescent polymers have been extensively studied [4]. Research on fluorescent material has attracted great attentions due to wide range of applications such as clean energy technologies [5], explosive sensing, $\mathrm{pH} /$ temperature sensor, biological imaging [6], life science, material science, ultrasensitive molecular diagnosis and novel light-emitting nano devices [7], and biological detection schemes, smart polymer machines, fluorescent chemo sensor, fluorescent molecular thermometers, fluorescent imaging, drug delivery carriers, and so on [8,9]. Different methods have been used developed to synthesize fluorescent polymers by many research groups, with new architecture which contain various amounts of fluorophores and show bright fluorescence are synthesized for various applications [10,11].Research on fluorophore-enriched polymers has become an interesting field because of their multipurpose applications as luminescent probes in various areas[12-15]. In general, there are two ways to synthesize such fluorophore-enriched polymers. Fluorescent polymers can be synthesized by polymerization of fluorescent functional monomers, using fluorescent compounds as initiator, fluorescent compounds as chain transfer agents, chemical bonding between fluorescent groups and polymers, and polymerization of nonfluorescent functional monomer[16-20], the second is the chemical variation of polymers by 
fluorescent molecules or fluorescent oligomers [21,22]. The aim of present work was to synthesize polyesters with high fluorescence intensity for the coming use in different field.

\section{Experiment work}

\subsection{Material and Methods}

Freshly prepared double distilled water was used for the preparation of solutions. Chemicals such as Sodium hydroxide pallets, Sodium bicarbonate, Thionyl chloride, Cetramide were used as received. The solvents carbon tetrachloride, chloroform, methanol, ethanol, acetone, Benzene, n-butanol, ethylacetate, amyl acetate, isoamyl acetate, dimethyl formamide(DMF), dimethyl sulfoxide(DMSO) were received from Merck. Cyanuric chloridewas purified by repeated crystallization from pure benzene(m.p146 $\left.{ }^{\circ} \mathrm{C}\right)$. pipridine $(\mathrm{BDH})$, Phenolphthalein (BDH LR),Catechol, Diethylene glycol, Ethylene glycol, Hydroquinone, Resorcinol, 1,4-dihydroxy Anthraquinone, 1,5-dihydroxy Anthraquinone, 1,8-dihydroxy Anthraquinone (Cibatul,Atul) were received and purified by recrystallization from rectified spirit.

\subsection{Synthesis of Monomer PCT}

\subsubsection{Synthesis of 2, 4-dichloro-6-(Piperidinyl)-1, 3, 5-triazine [PT]}

A solution of cyanuric Chloride $(18.44 \mathrm{~g}, 0.1 \mathrm{~mol})$ in a $60 \mathrm{ml}$ Acetone was added with stirring to a cooled solution $\left(0-5^{\circ} \mathrm{C}\right)$ of sodium bicarbonate $(10.6 \mathrm{~g})$ in $100 \mathrm{ml}$ of distilled water, in a threenecked flask $(250 \mathrm{ml})$ equipped with a mechanical stirrer. This resulted in the formation of slurry of cyanuric chloride. A solution of piperidine $(10.2 \mathrm{ml}, 0.1 \mathrm{~mol})$ in $10 \mathrm{ml}$ of acetone was added to the cold slurry of cyanuric chloride. The mixture was stirred for 2 hour at $0-5^{\circ} \mathrm{C}$. The white colored product was filtered, and recrystallized from ethanol and dried in vacuum desiccators. The yield was $82 \%$. M. P. $120^{\circ} \mathrm{C}$.

\subsubsection{Synthesis of 6-(N-Piperidinyl)-2,4-bis-(7-Hydroxy-Coumarin-3-carboxylic acid)-1,3,5- triazine [PCT]}

A solution of 2,4-dichloro-6-(Piperidinyl)-1,3,5-triazine [PT] $(23.3 \mathrm{~g}, 0.1 \mathrm{~mol})$ in $40 \mathrm{ml}$ of acetone was mixed with solution of $\mathrm{NaOH}(16 \mathrm{~g}, 0.4 \mathrm{~mol})$ and 7 -Hydroxy-Coumarin-3-carboxylic acid $(41.2 \mathrm{~g}, 0.2 \mathrm{~mol})$ in $80 \mathrm{ml}$ double distilled water. Reaction was stirred for $2 \mathrm{hr}$ at room temperature and $2 \mathrm{hr}$ at $80^{\circ} \mathrm{C}$. Separated solid was collected and washed with hot water. Product was dried in vacuum at $100^{\circ} \mathrm{C}$. The yield was $86 \%$. The product was recrystallized from acetone. M. P. $153^{\circ} \mathrm{C}$.

\subsubsection{Synthesis of 6-(N-Piperidinyl)-2,4-bis-(7-Hydroxy-Coumarin-3-carbonyl Chloride) 1,3,5- triazine [PCTC]}

Thionyl chloride $(11.9 \mathrm{ml}, 0.1 \mathrm{~mol})$ was added into 6-(N-Piperidinyl)-2,4-bis-(7-HydroxyCoumarin-3-carboxylic acid)-1,3,5-triazine [PCT] $(5.68 \mathrm{~g}, 01 \mathrm{~mol})$ in a dry round bottom flask. The reaction mixture was refluxed at $78^{\circ} \mathrm{C}$ for $2 \mathrm{hr}$. At the end of the reaction, excess thionyl chloride was distilled and dry product was collected. The yield was about $78 \%$. The product was recrystallized from dimethyl formamide. M. P. $218^{\circ} \mathrm{C}$.

\subsection{Synthesis of Polyesters}

6-(N-Piperidinyl)-2,4-bis-(7-Hydroxy-Coumarin-3-carbonyl Chloride)-1,3,5-triazine [PCTC] $(0.01 \mathrm{~mol})$ in the minimum quantity of DMF (approx. $10 \mathrm{ml})$ was stirred into round bottom flask, then initiator citrimide $(0.25 \mathrm{~g})$ was added and heated up to $150^{\circ} \mathrm{C}$. Then 1,4 -Anthraquinone $(0.02 \mathrm{~mol})$ was added. The reaction temperature was raised to $160-180^{\circ} \mathrm{C}$ and heated for $8 \mathrm{hrs}$. The reaction mixture was cooled and poured with constant stirring in $250 \mathrm{ml}$ of ice-cooled water. Solid was filtered, washed with hot water and dried. The yield was about $79 \%$. The other polyesters from 6-(N-Piperidinyl)-2,4-bis-(7-Hydroxy- Coumarin-3-carbonyl Chloride)-1,3,5-triazine [PCTC] and various diols were synthesized by the similar method. PHE-1 to PHE-10 polymers are synthesised by using catechol, diethylene glycol, ethylene glycol, hydroquinone, phenolphthalein, resorcinol, bisphenol-A, 1,4anthraquinone, 1,5anthraquinone, 1,8 anthraquinone respectively. 


\subsubsection{Properties of Polyesters}

Polyesters prepared from coumarin and a variety of diols have exclusive colours. Coumarin and piperidine based polyesters show different colours. Most of the polyesters are brown in colour. PHE-1, PHE-3 were dark brown, PHE-2, PHE-6, PHE-7 were light brown, but PHE-4, PHE-5, PHE-8, PHE-9, and PHE-10 were pink, coffee, maroon, golden and black respectively.

\subsubsection{Solubility}

Relative solubility of various polyesters obtained from coumarin and piperidine in different solvents were carried out at room temperature and $50^{\circ} \mathrm{C}$. The solubility of the polyesters in different solvents reveals that polyesters were insoluble in aliphatic chlorinated solvents like chloroform, carbon tetrachloride. It was also found that polyesters were insoluble in halogenated and nonhalogenated aromatic compounds like chlorobenzene, benzene and ether. Polyesters were soluble in dimethyl formamide, dimethyl sulfoxide, tetra hydro furan, ether and ethyl acetate Polyesters were partly soluble at room temperature in methanol, ethanol, n-butanol, and isopropyl alcohol but some of polyesters are soluble at higher temperature which is described in table-1.

Table 1. Relative solubility of polyesters

\begin{tabular}{|c|c|c|c|c|c|c|c|c|c|c|}
\hline Solvent & $\underset{1}{7}$ & 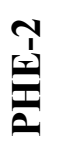 & $\begin{array}{l}n \\
0 \\
0 \\
0 \\
0\end{array}$ & 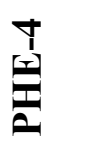 & $\begin{array}{l}n \\
1 \\
0 \\
0 \\
0\end{array}$ & $\begin{array}{l}0 \\
1 \\
0 \\
0 \\
0 \\
0\end{array}$ & 式 & $\begin{array}{l}\infty \\
1 \\
0 \\
0 \\
0\end{array}$ & $\begin{array}{l}a \\
0 \\
0 \\
0\end{array}$ & 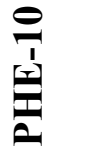 \\
\hline DMF & ++ & ++ & ++ & ++ & ++ & ++ & ++ & ++ & ++ & ++ \\
\hline DMSO & ++ & ++ & ++ & ++ & ++ & ++ & ++ & ++ & ++ & ++ \\
\hline Chloroform & -- & -- & -- & -- & -- & -- & -- & - & -- & -- \\
\hline $\mathrm{CCl}_{4}$ & -- & -- & -- & -- & -- & -- & -- & -- & -- & -- \\
\hline Acetone & ++ & ++ & ++ & ++ & -- & ++ & -- & ++ & ++ & ++ \\
\hline Benzene & -- & -- & -- & -- & -- & -- & -- & -- & -- & -- \\
\hline Cl-Benzene & -- & -- & -- & -- & -- & -- & -- & -- & -- & -- \\
\hline Methanol & - \pm & - \pm & - \pm & - \pm & - \pm & - \pm & - \pm & - \pm & - \pm & - \pm \\
\hline Ethanol & - \pm & - \pm & - \pm & - \pm & - \pm & - \pm & - \pm & - \pm & - \pm & - \pm \\
\hline THF & ++ & ++ & ++ & ++ & ++ & ++ & ++ & ++ & ++ & ++ \\
\hline n-Butanol & - \pm & - \pm & - \pm & - \pm & - \pm & - \pm & - \pm & - \pm & - \pm & - \pm \\
\hline IPA & \pm+ & \pm+ & \pm \pm & \pm+ & \pm+ & \pm+ & \pm \pm & \pm+ & \pm+ & \pm+ \\
\hline Ether & -- & -- & -- & -- & -- & -- & -- & -- & -- & -- \\
\hline Ethyl Acetate & ++ & ++ & ++ & ++ & ++ & ++ & ++ & ++ & ++ & ++ \\
\hline
\end{tabular}

$(+=)$ Soluble, $(-=)$ Insoluble, $( \pm=)$ Partly soluble

\subsubsection{Viscosity}

Intrinsic, reduced and inherent viscosity for all the polyesters at various concentrations were determined at $25 \pm 0.1^{\circ} \mathrm{C}$. The relative $\left(\eta_{\text {rel }}\right)$ and specific $\left(\eta_{\text {sp }}\right)$ viscosities, reduced and inherent viscosities were calculated from experimental data. Typical Huggins and Kraemer plots were used to obtain intrinsic viscosity for some of polyesters. Intrinsic, reduced and inherent viscosities along with Huggin's and Kraemer's constants for 1\% solution are shown in figure 1.

The observations of intrinsic viscosities of Polyesters PHE 1-10 reveals that PHE-7 which contain Bisphenol $-\mathrm{A}$ as diol has the highest solution viscosity and which can be due to high molecular weight compound, whereas PHE-3 has the lowest intrinsic viscosity which contain aliphatic Ethylene Glycol. The range of viscosity in this series was $0.455-0.615 \mathrm{~g} / \mathrm{dl}$. The polymers which contain aromatic diols have high viscosity and the aliphatic diols have low viscosity such as PHE-3 and PHE-2 which has diethylene glycol and ethylene glycol as diols. The viscosity of PHE-5 is less than PHE-7 but higher than the rest of the polyesters. The intrinsic viscosity of the polyesters obtained follows the sequence given here which is described in table 2. 
PHE-3 $<$ PHE-2 < PHE-1 $<$ PHE-8 $<$ PHE-6 $<$ PHE-4 $<$ PHE-9 $<$ PHE-10 $<$ PHE-5 $<$ PHE-7

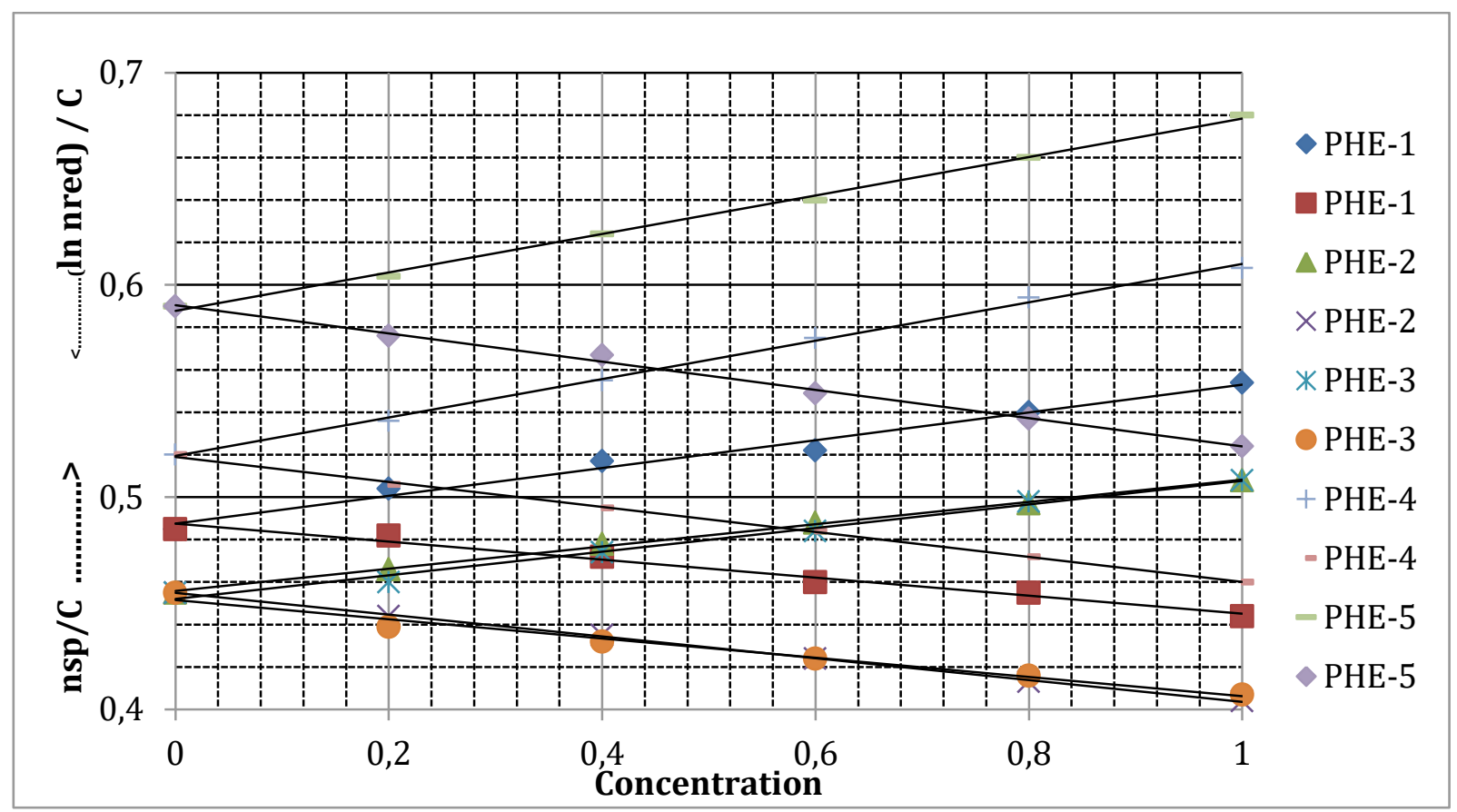

Figure 1. Typical Huggins and Kraemer plots for intrinsic viscosity PHE-1 to PHE-5

Table 2. Various viscosity values and Huggins's and Kraemer's constants

\begin{tabular}{|c|c|c|c|c|c|}
\hline Polymer & $\begin{array}{c}\text { Intrinsic viscosity } \\
\qquad[\eta]\end{array}$ & $\begin{array}{c}\text { Reduced } \\
\text { viscosity } \\
\eta_{\text {sp }} / C\end{array}$ & $\begin{array}{l}\text { Inherent } \\
\text { viscosity } \\
\text { ln } \eta_{\text {rel }} / C\end{array}$ & $\begin{array}{c}\text { Huggin's } \\
\text { constant } K \text { ' }\end{array}$ & $\begin{array}{c}\text { Kraemer's } \\
\text { constant } \\
\text { K" }\end{array}$ \\
\hline PHE-1 & 0.492 & 0.552 & 0.434 & 0.242 & 0.239 \\
\hline PHE-2 & 0.475 & 0.508 & 0.407 & 0.144 & 0.302 \\
\hline PHE-3 & 0.455 & 0.507 & 0.402 & 0.251 & 0.256 \\
\hline PHE-4 & 0.510 & 0.559 & 0.444 & 0.206 & 0.275 \\
\hline PHE-5 & 0.590 & 0.679 & 0.522 & 0.255 & 0.195 \\
\hline PHE-6 & 0.505 & 0.561 & 0.449 & 0.229 & 0.219 \\
\hline PHE-7 & 0.615 & 0.709 & 0.536 & 0.248 & 0.208 \\
\hline PHE-8 & 0.494 & 0.583 & 0.445 & 0.376 & 0.194 \\
\hline PHE-9 & 0.515 & 0.601 & 0.474 & 0.324 & 0.154 \\
\hline PHE-10 & 0.535 & 0.591 & 0.464 & 0.250 & 0.250 \\
\hline
\end{tabular}

\subsubsection{Characterization}

All the synthesised polyesters were characterised by visible absorption spectra, some representative IR spectra and NMR spectra. The visible absorption spectra of all synthesised polyesters have been recorded in DMF and observed in range of 550 to $380 \mathrm{~nm}$. The colour observed for each of the polyester was due to oscillation of electrons and the presence of substituents.

\subsubsection{IR Spectra}

IR spectra of polyester PHE-3 showed O-H stretching vibration of -OH group at $3445 \mathrm{~cm}^{-1}$, $\mathrm{N}-\mathrm{H}$ stretching vibration of secondary amine at $3424 \mathrm{~cm}^{-1}, \mathrm{C}-\mathrm{H}$ stretching vibration of $-\mathrm{OCH}_{3}$ group at $2960 \mathrm{~cm}^{-1}, \mathrm{C}-\mathrm{H}$ stretching vibration of $-\mathrm{CH}_{2}$ - group at $2842 \mathrm{~cm}^{-1}, \mathrm{C}=\mathrm{C}$ stretching vibration of aromatic ring at $1607 \mathrm{~cm}^{-1}$.

IR spectra of polyester PHE-6 showed O-H stretching vibration of -OH group at $3438 \mathrm{~cm}^{-1}$, $\mathrm{N}-\mathrm{H}$ stretching vibration of secondary amine at $3424 \mathrm{~cm}^{-1}, \mathrm{C}-\mathrm{H}$ stretching vibration of -OCH3 group 
at $2940 \mathrm{~cm}^{-1}, \mathrm{C}-\mathrm{H}$ stretching vibration of $-\mathrm{CH}_{2^{-}}$group at $2843 \mathrm{~cm}^{-1}, \mathrm{C}=\mathrm{O}$ stretching vibration of COOR group at $1708 \mathrm{~cm}^{-1}$.

IR spectra of polyester PHE-7 showed O-H stretching vibration of -OH group at $3291 \mathrm{~cm}^{-1}$, $\mathrm{N}-\mathrm{H}$ stretching vibration of secondary amine at $3424 \mathrm{~cm}^{-1}, \mathrm{C}-\mathrm{H}$ stretching vibration of $-\mathrm{OCH}_{3}$ group at $2960 \mathrm{~cm}^{-1}, \mathrm{C}-\mathrm{H}$ stretching vibration of $-\mathrm{CH}_{2}$ - group at $2845 \mathrm{~cm}^{-1}, \mathrm{C}=\mathrm{C}$ stretching vibration of aromatic ring at $1608 \mathrm{~cm}^{-1}, \mathrm{C}-\mathrm{N}$ stretching vibration of tertiary amine group at $1533 \mathrm{~cm}^{-1}$.

IR spectra of polyester PHE-9 showed O-H stretching vibration of -OH group at $3620 \mathrm{~cm}^{-1}$, $\mathrm{N}-\mathrm{H}$ stretching vibration of secondary amine at $3544 \mathrm{~cm}^{-1}, \mathrm{C}-\mathrm{H}$ stretching vibration of -OCH3 group at $2440 \mathrm{~cm}^{-1}, \mathrm{C}-\mathrm{H}$ stretching vibration of $-\mathrm{CH}_{2}$ - group at $2843 \mathrm{~cm}^{-1}, \mathrm{C}=\mathrm{O}$ stretching vibration of COOR group at $1708 \mathrm{~cm}^{-1}$.

Examination of IR absorption frequencies reveals that the polyesters exhibit strong or moderately strong absorption at a frequency of $803 \mathrm{~cm}^{-1}$ and $1464-1511 \mathrm{~cm}^{-1}$ which may be attributed to out of plane and in-plane vibrations of s-triazine ring respectively, $1737 \mathrm{~cm}^{1}$ and $1612 \mathrm{~cm}^{-1}$ which may be attributed to vibrations involving lactone and ester groups respectively.

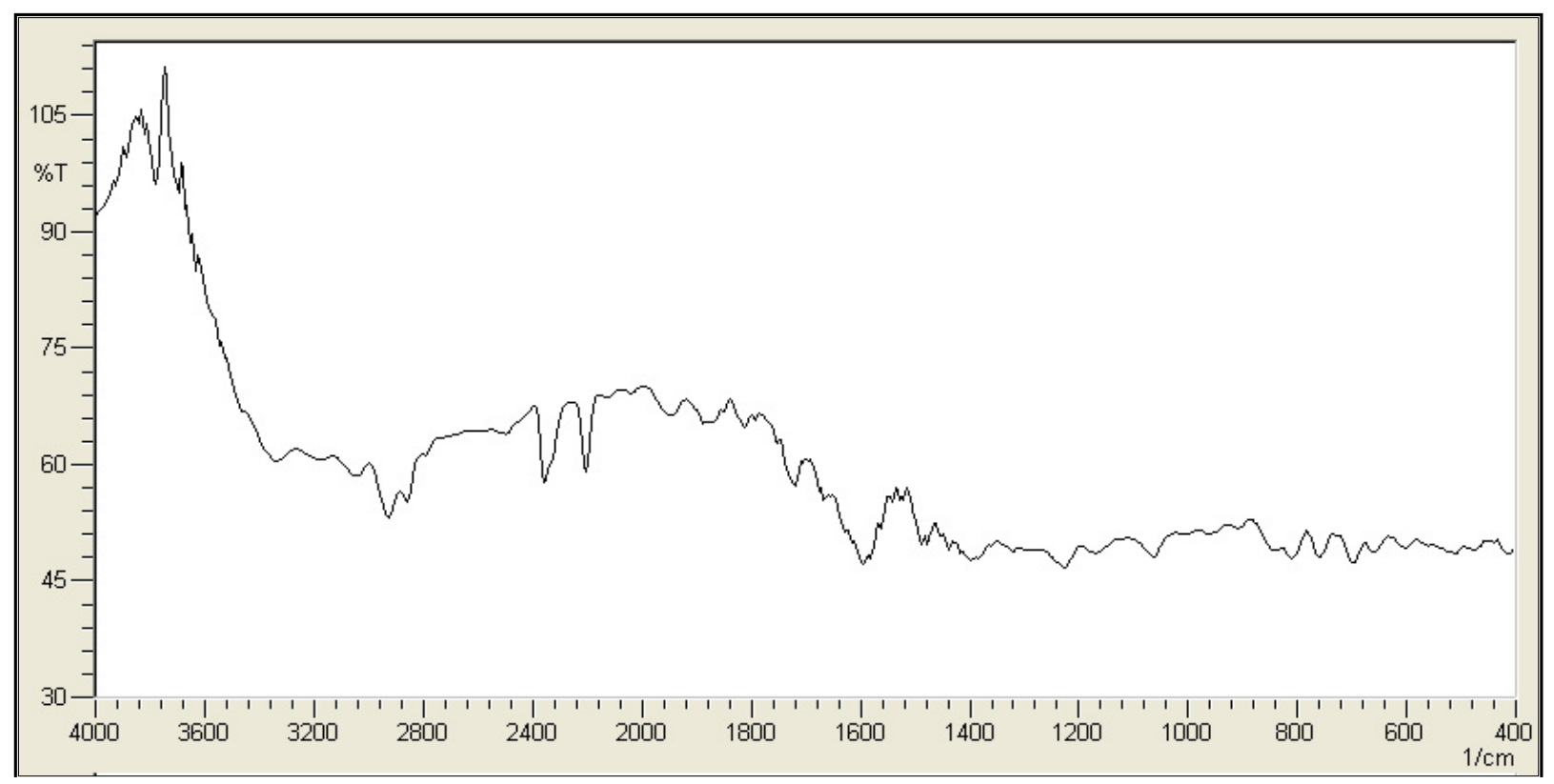

Figure 2. IR spectrum of PHE-3

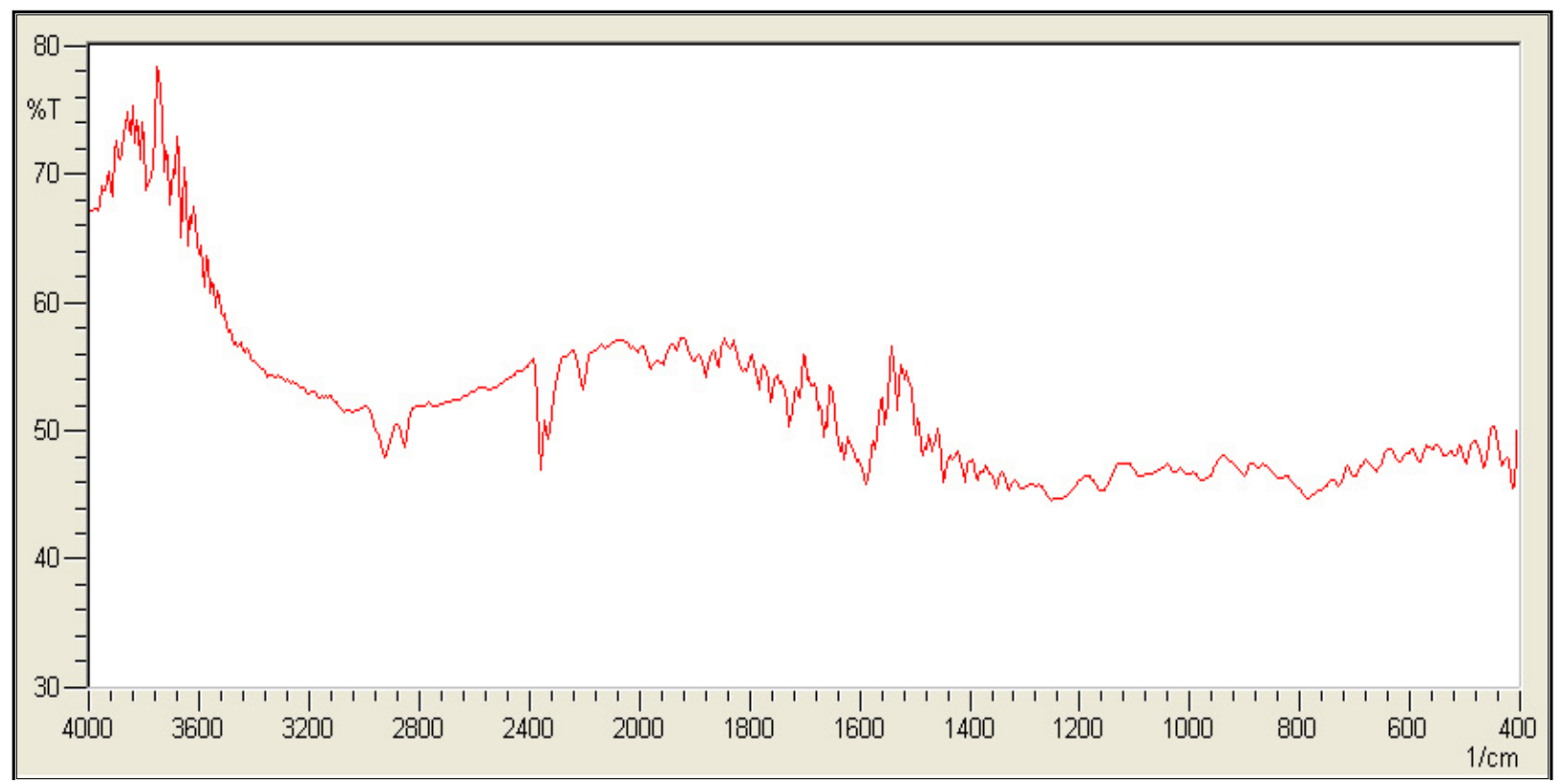

Figure 3. IR spectrum of PHE-6 


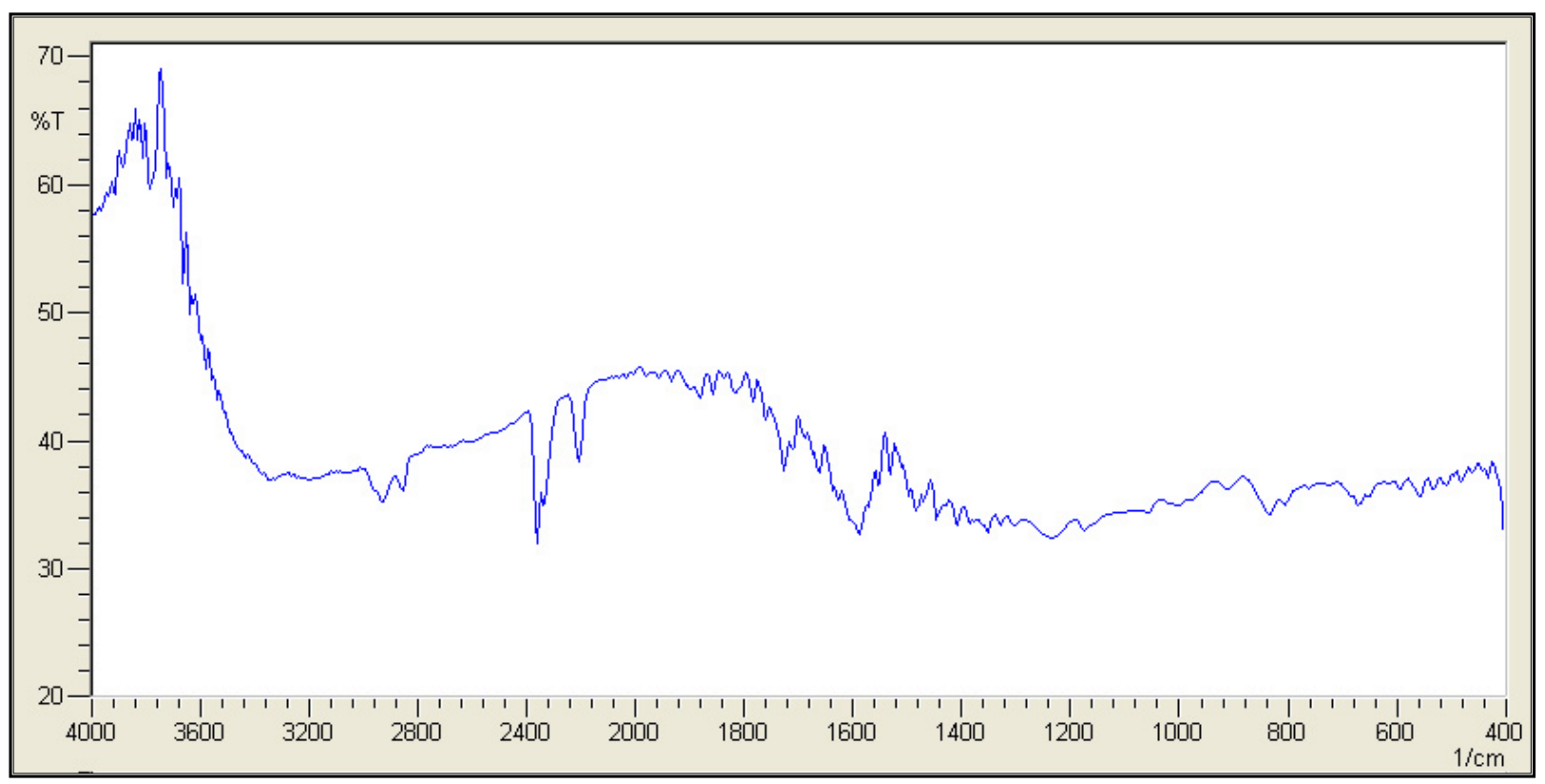

Figure 4. IR spectrum of PHE-7

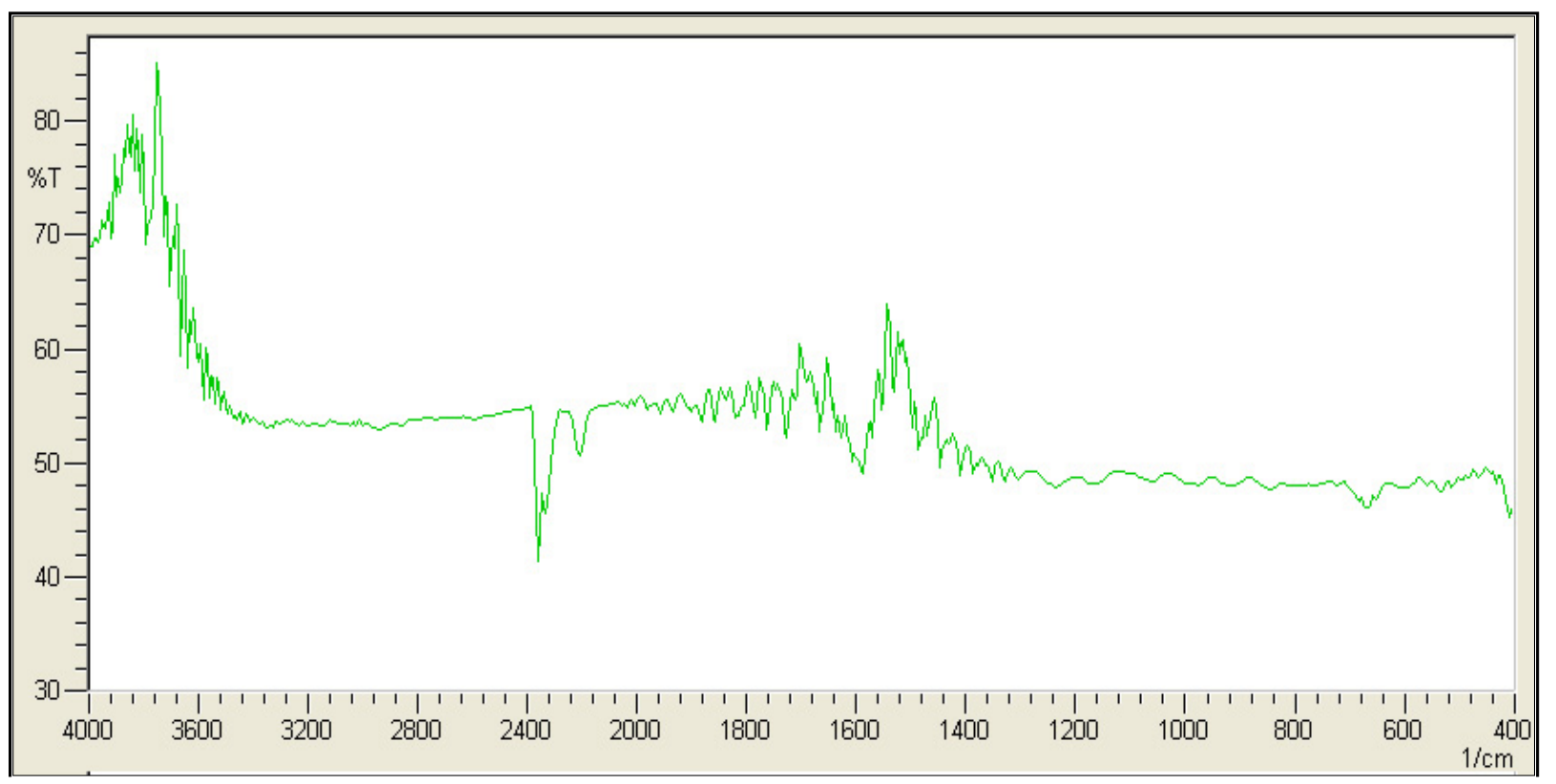

Figure 5. IR spectrum of PHE-9

\subsection{6 ${ }^{1}$ HNMR Spectra}

In figure (6) and figure 7, ${ }^{1} \mathrm{H}-\mathrm{NMR}$ spectrum of polyesters PHE-3 and PHE-6 singlet appear at $3.94 \delta$ were of $-\mathrm{NH}$-protons, the presence of $-\mathrm{CH}_{2}$ at 3.67 and $3.69 \delta$. The protons at $4.90 \delta$, and 6.78-7.80 were of $-\mathrm{OH}$ proton and aromatic protons. The multiple signals of aromatic protons

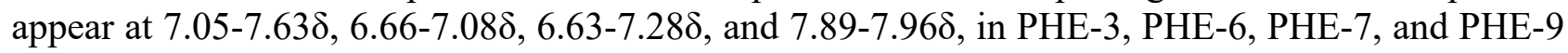
respectively. The shift at $0.87 \delta$ indicates the presence of $-\mathrm{CH}_{2}$ - group of Diethylene Glycol in figure (6). Chemical shifts at 3.63-3.69 $\delta$ prove the presence of $-\mathrm{CH}_{2}$ - group in piperidine. A singlet of $1.55 \delta$ gives the conformation of $-\mathrm{CH}_{3}$ group of Bisphenol-A in figure (6). In the same way, in figure (7), the presence of aromatic protons appears at 6.66-7.08 $\delta$ and the presence of $-\mathrm{CH}_{2}$ at $3.7 \delta$ $3.8 \delta$ in PHE- 6 . The protons at $6.8 \delta, 6.7-6.9 \delta$ proves the presence of aromatic protons in PHE-7 and PHE-9 in figure (8) and figure (9). Chemical shifts at $2.2-2.6 \delta, 2.5 \delta$ prove the presence of ester linkage in PHE-7 and PHE-9. 


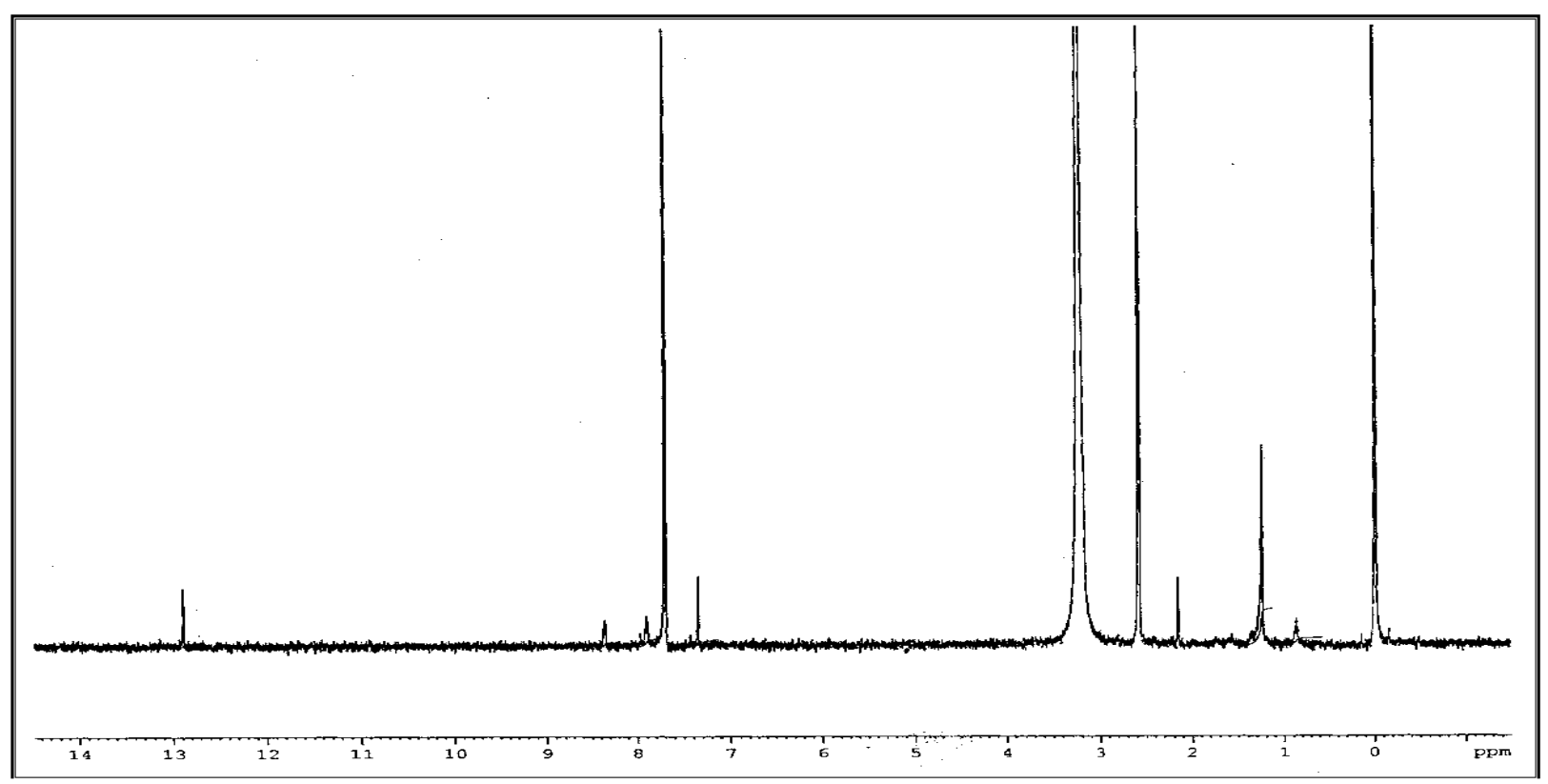

Figure 6. ${ }^{1} \mathrm{H}$-NMR spectrum of PHE-3

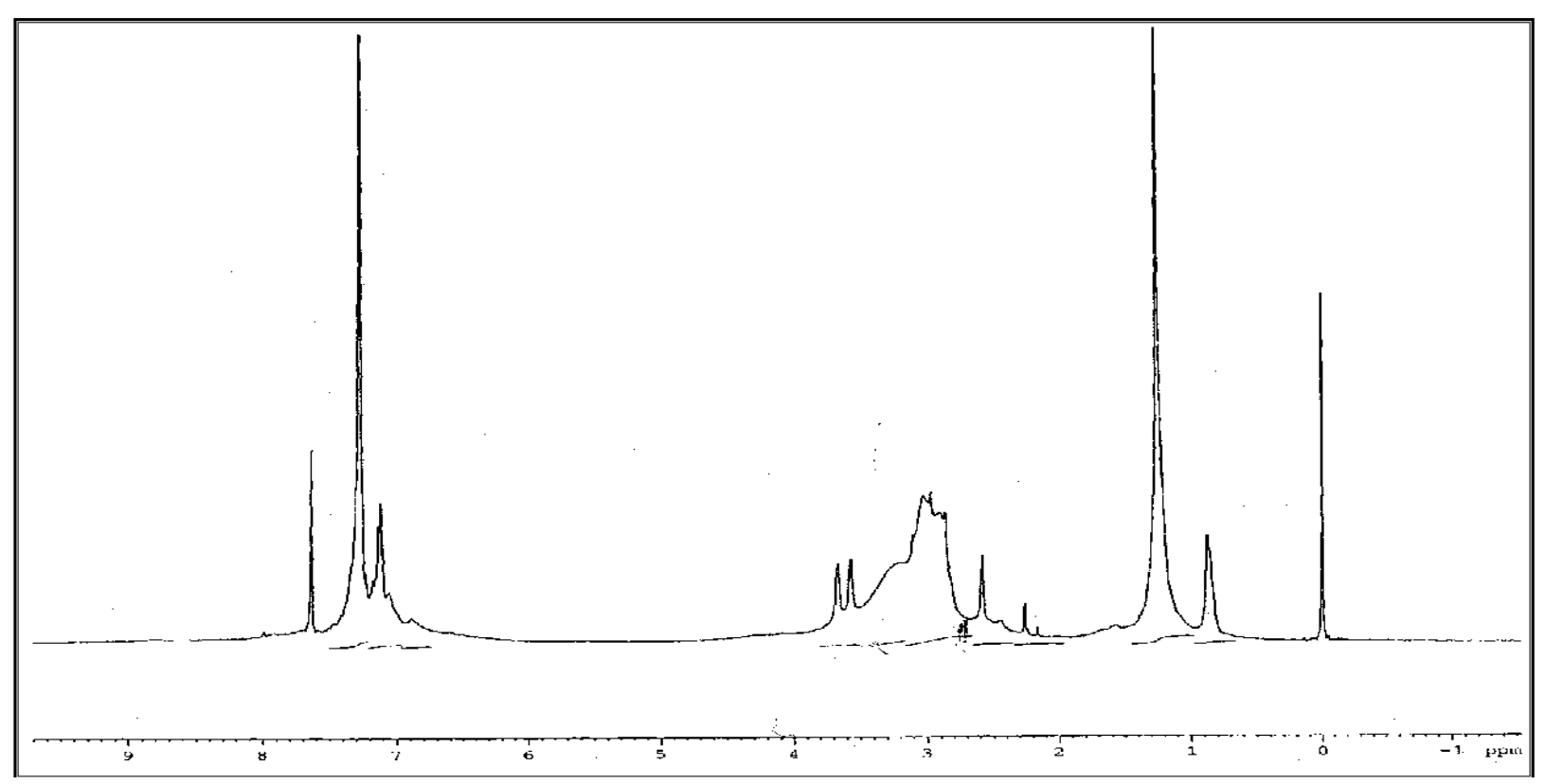

Figure 7. ${ }^{1} \mathrm{H}-\mathrm{NMR}$ spectrum of PHE-6 


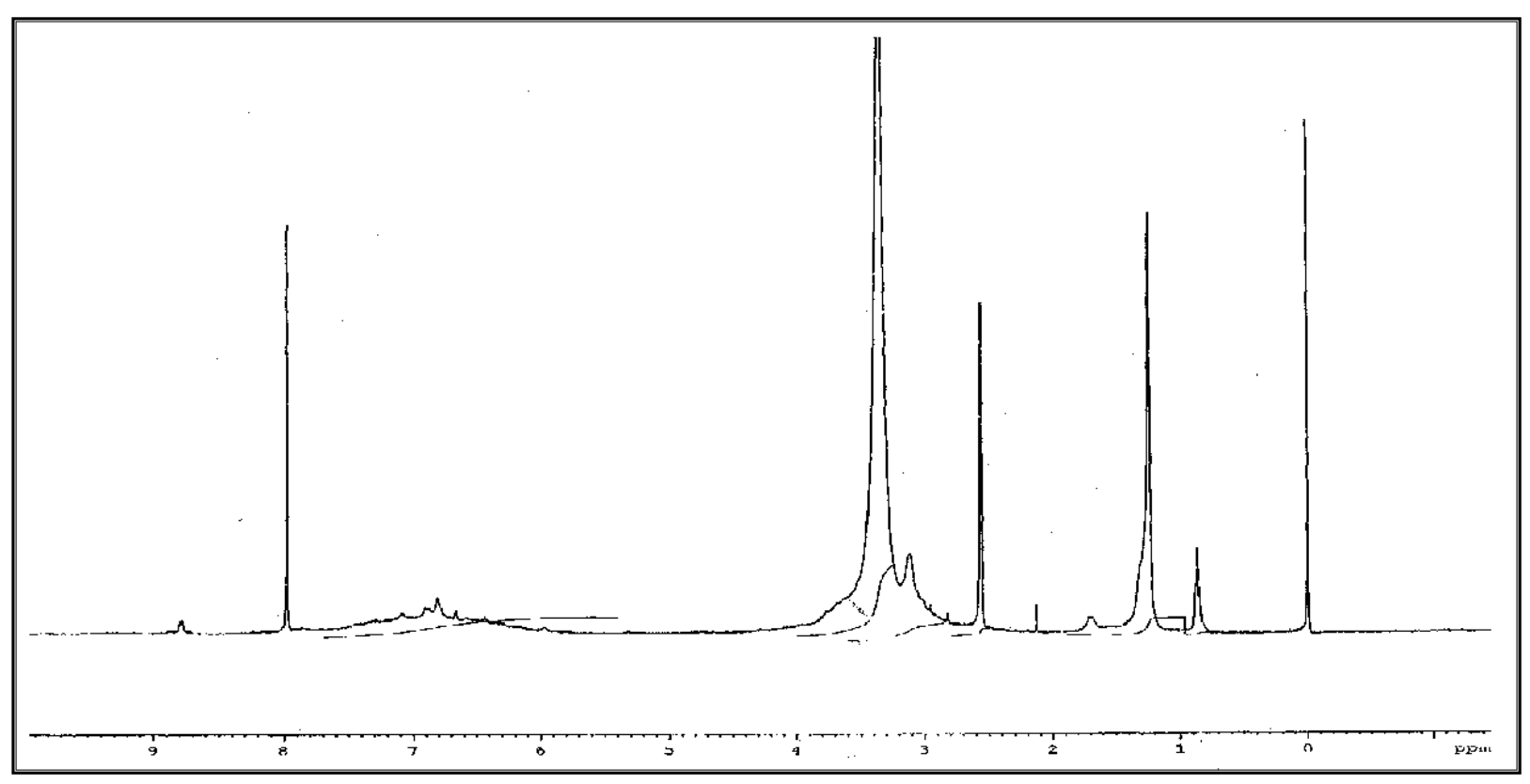

Figure 8. ${ }^{1} \mathrm{H}-\mathrm{NMR}$ spectrum of PHE-7

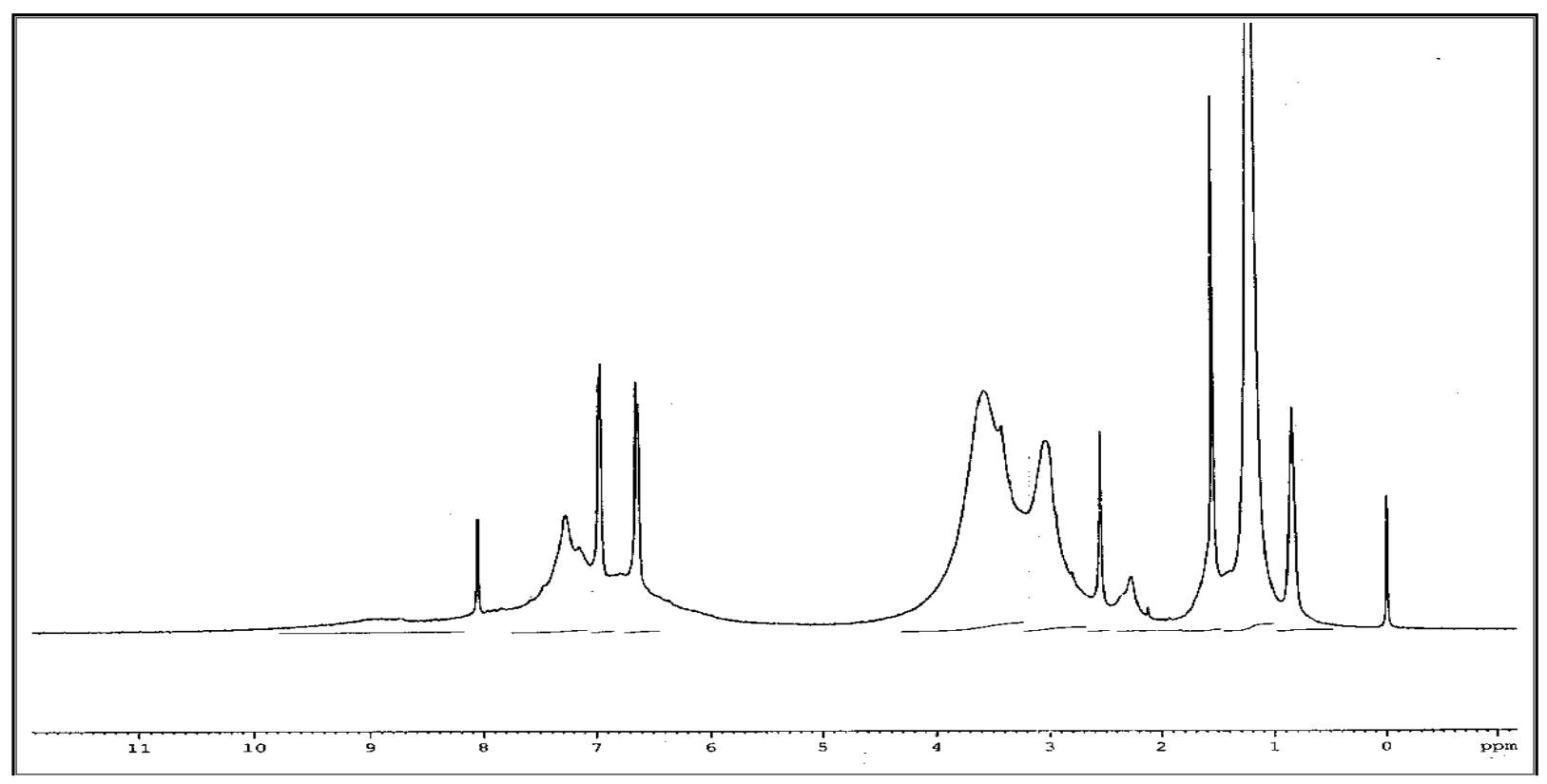

Figure 9. ${ }^{1} \mathrm{H}-\mathrm{NMR}$ spectrum of PHE-9

\subsubsection{Thermogravimetric analysis:}

The TGA data were used to determine the initial degradation temperature, degradation rate, residual weight at the end of degradation, and degradation kinetic parameters. The weight loss of polyesters during thermal degradation is a function of degradation rate and degradation time. At higher heating rate, although the degradation rate was higher, the time to reach a given temperature became shorter and the residual weight at a given temperature during thermal degradation may be higher. The remaining solid residue after complete pyrolysis was char and ash. TGA was used to determine the thermal degradation characteristics and kinetic parameters. An attempt is made to assess the thermal stability of some of the polyesters qualitatively based on visual obtained thermograms. $T_{0}$ and $T_{10}$ are some of the main criteria of the thermal stability of the polyesters. The higher the $\mathrm{T}_{0}$ and $\mathrm{T}_{10}$, the higher will be the heat stability of polyesters. TGA curve obtains at a scan rate of $10^{\circ} \mathrm{C} / \mathrm{min}$ for polyesters. 


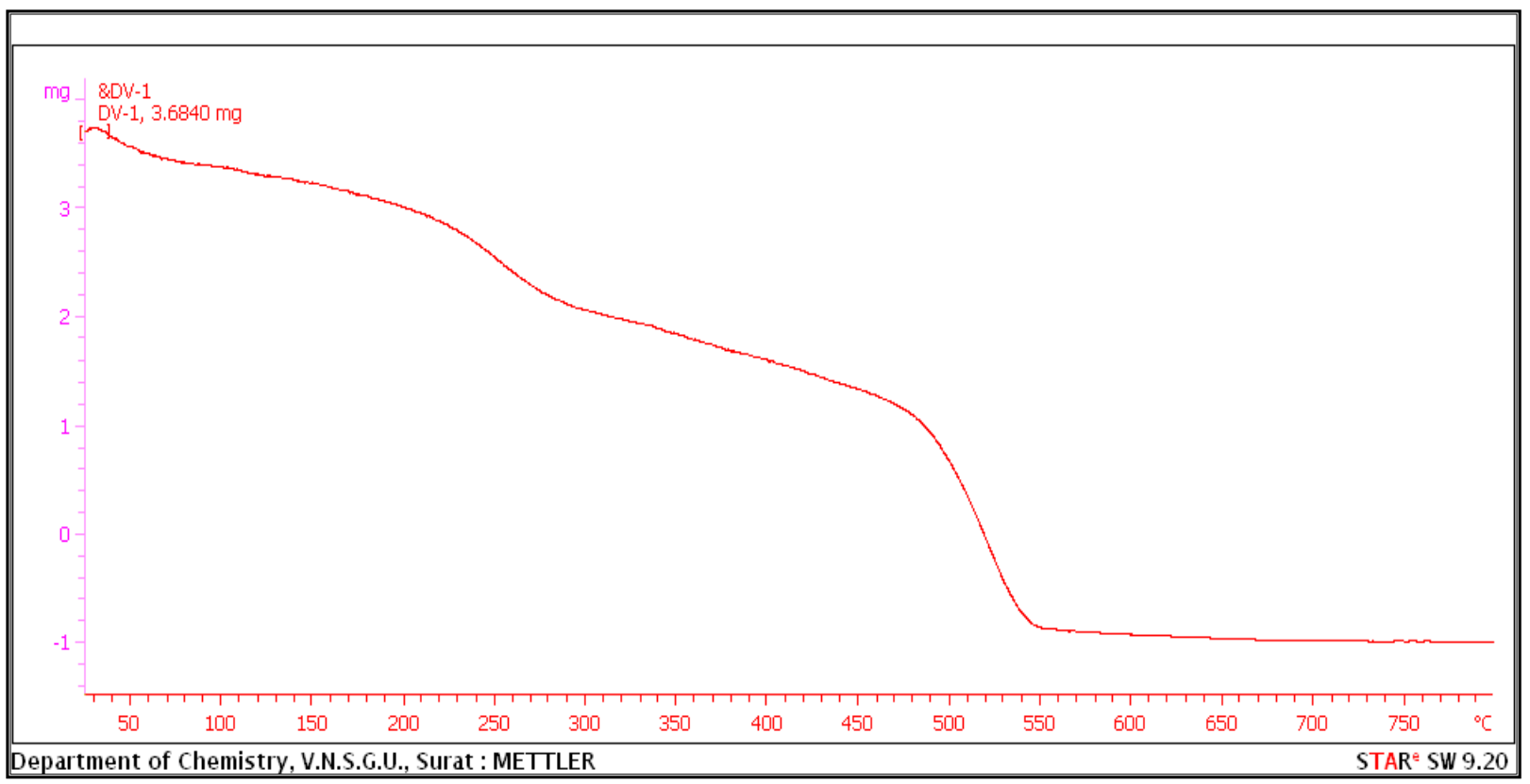

Figure 10. TGA OF PHE-3

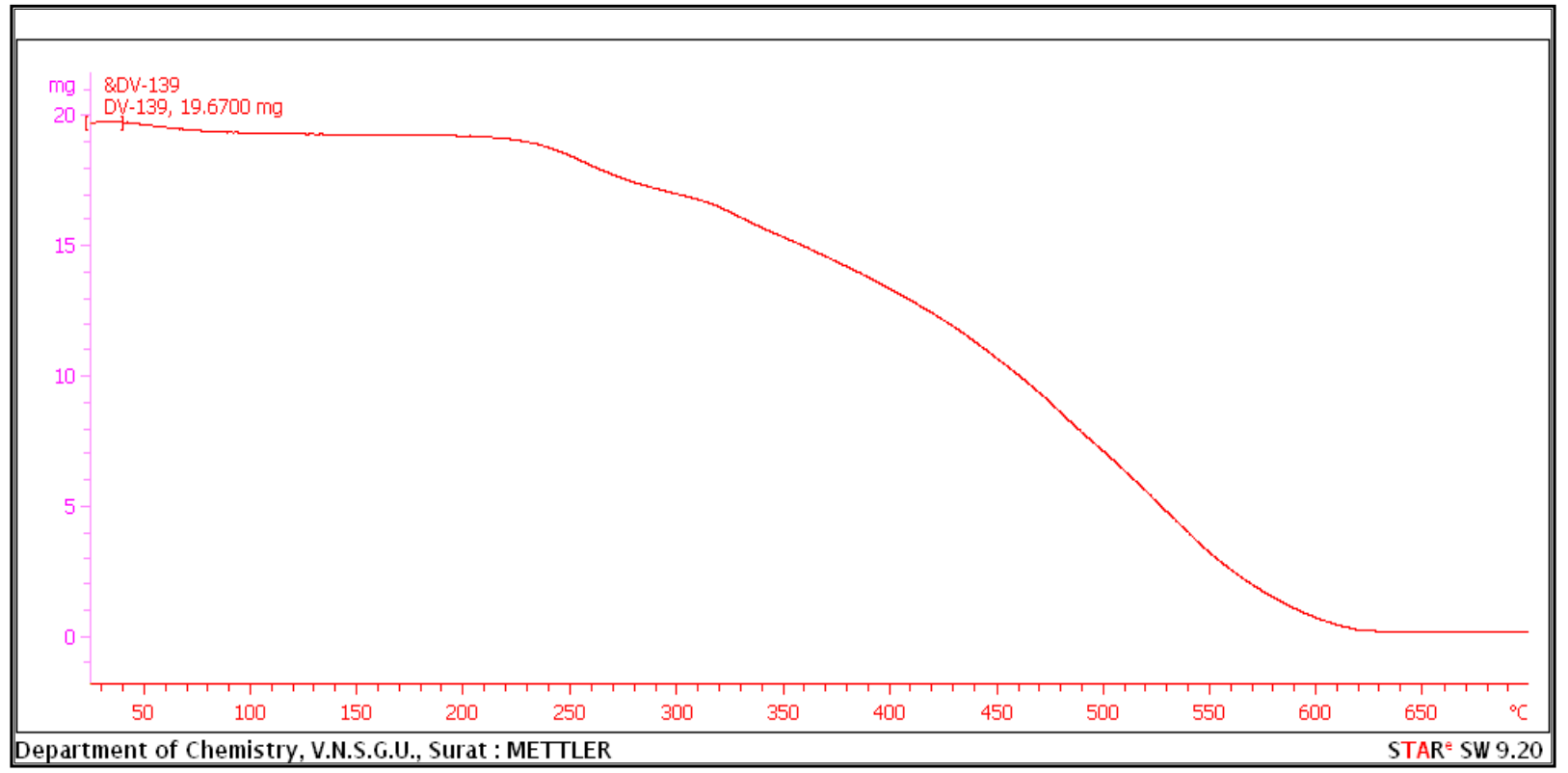

Figure 11. TGA OF PHE-6 


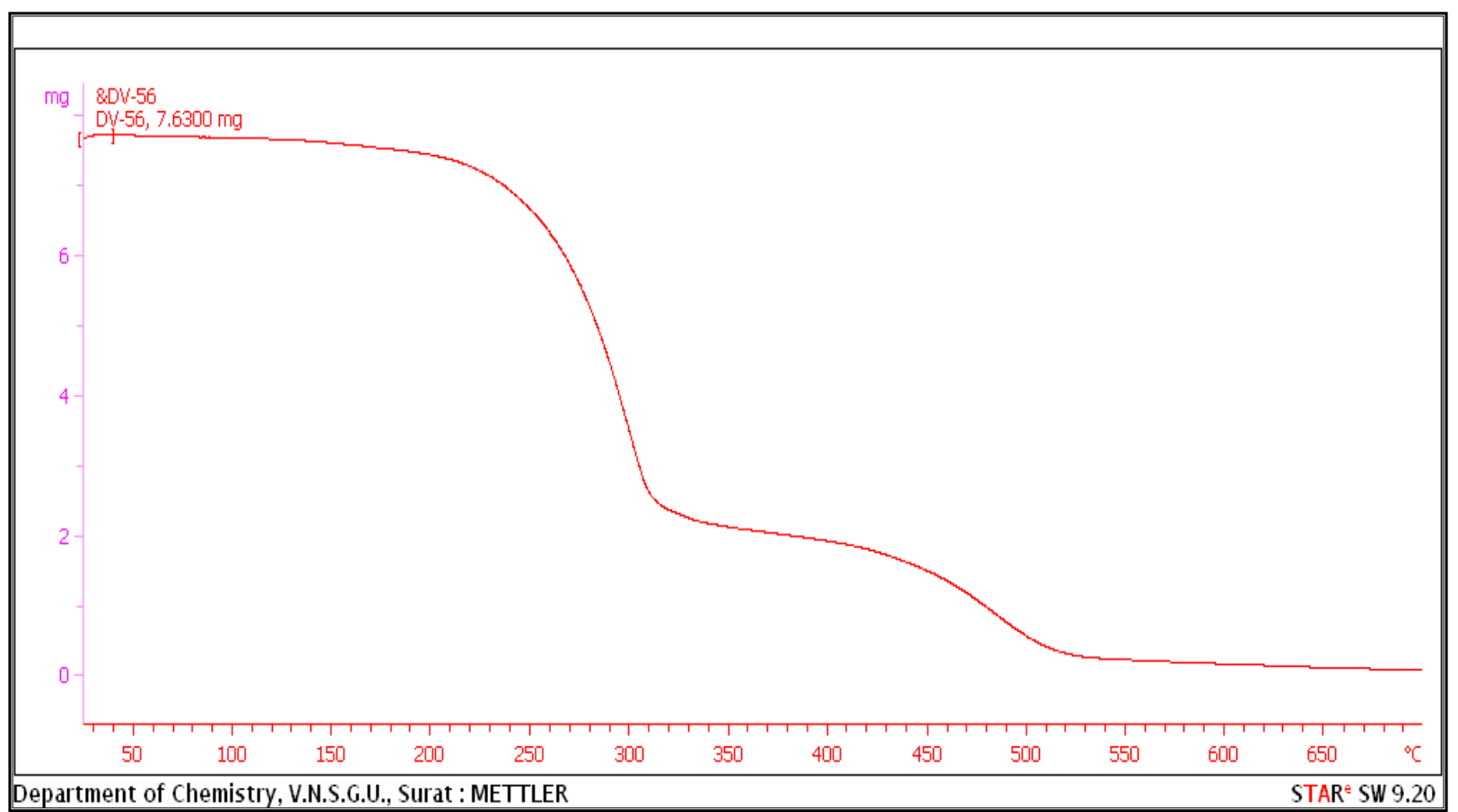

Figure 12. TGA OF PHE-7

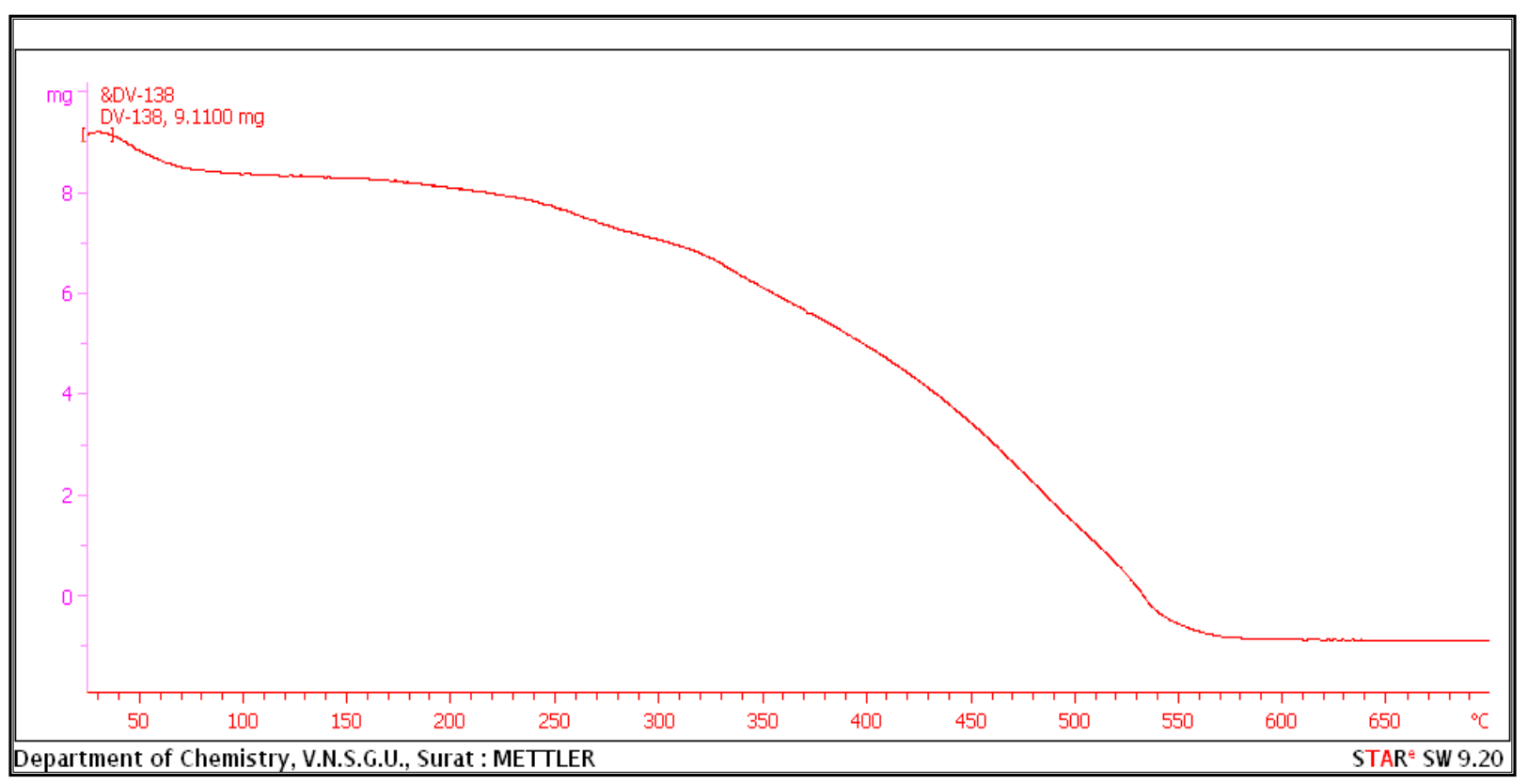

Figure 13. TGA OF PHE-9

The thermal properties of the PHE-3, PHE-6, PHE-7, and PHE- 9 were evaluated by TGA at heating rate of $10^{\circ} \mathrm{C} / \mathrm{min}$ under a nitrogen atmosphere. The $10 \%$ weight loss temperature of the aromatic polyesters in nitrogen was recorded at $300^{\circ} \mathrm{C}$ for PHE-3, PHE-6 PHE-7, and PHE-9. TGA thermogram of PHE-6 polyesters in figure (11) exhibited high thermal stability. The amount of residue of PHE-6 polyesters in a nitrogen atmosphere was more than $44 \%$ at $550^{\circ} \mathrm{C}$. The polyesters PHE-3, PHE-7 and PHE-9 were degraded at $530^{\circ} \mathrm{C}, 510^{\circ} \mathrm{C}, 540^{\circ} \mathrm{C}$ respectively. The high char yields of these polyesters could be ascribed due to their high aromatic content. The series of polyesters showed higher thermal stability compared to the corresponding counterpart without coumarin moiety. 


\subsubsection{Fluorescence Spectra:}

The fluorescence spectrums of synthesized polyesters PHE-3, PHE-6, PHE-7, PHE-9 and PHE-10 were coumarin based piperidine monomer with the Ethylene glycol, resorcinol, hydroquinone and 1,8 Anthraquinone as diols. Polyesters were dissolved in DMSO- $D_{6}$ and then excited at 190nm. Emission spectra were recorded between 110 and $800 \mathrm{~nm}$. Upon excitation at 110 $\mathrm{nm}$, the fluorescence spectrum of PHE-3, PHE-6, PHE-7, PHE-9 and PHE-10, indicates broaden emission range between $100-600 \mathrm{~nm}$ and emission peak in between $290 \mathrm{~nm}-300 \mathrm{~nm}$. The highest intensity peak was observed in figure (18) and the lowest intensity peak was observed in figure (14) due to aliphatic diol. The decrease of fluorescence intensity does not follow the first-order kinetics model. One can suggest that at least two processes are responsible for the decrease of fluorescence: (1) concentration of fluorescent decreases due to photo cyclization reaction, and (2) fluorescence photo quenching operates in this system via intermolecular mechanism of energy transfer in photo stationary state.

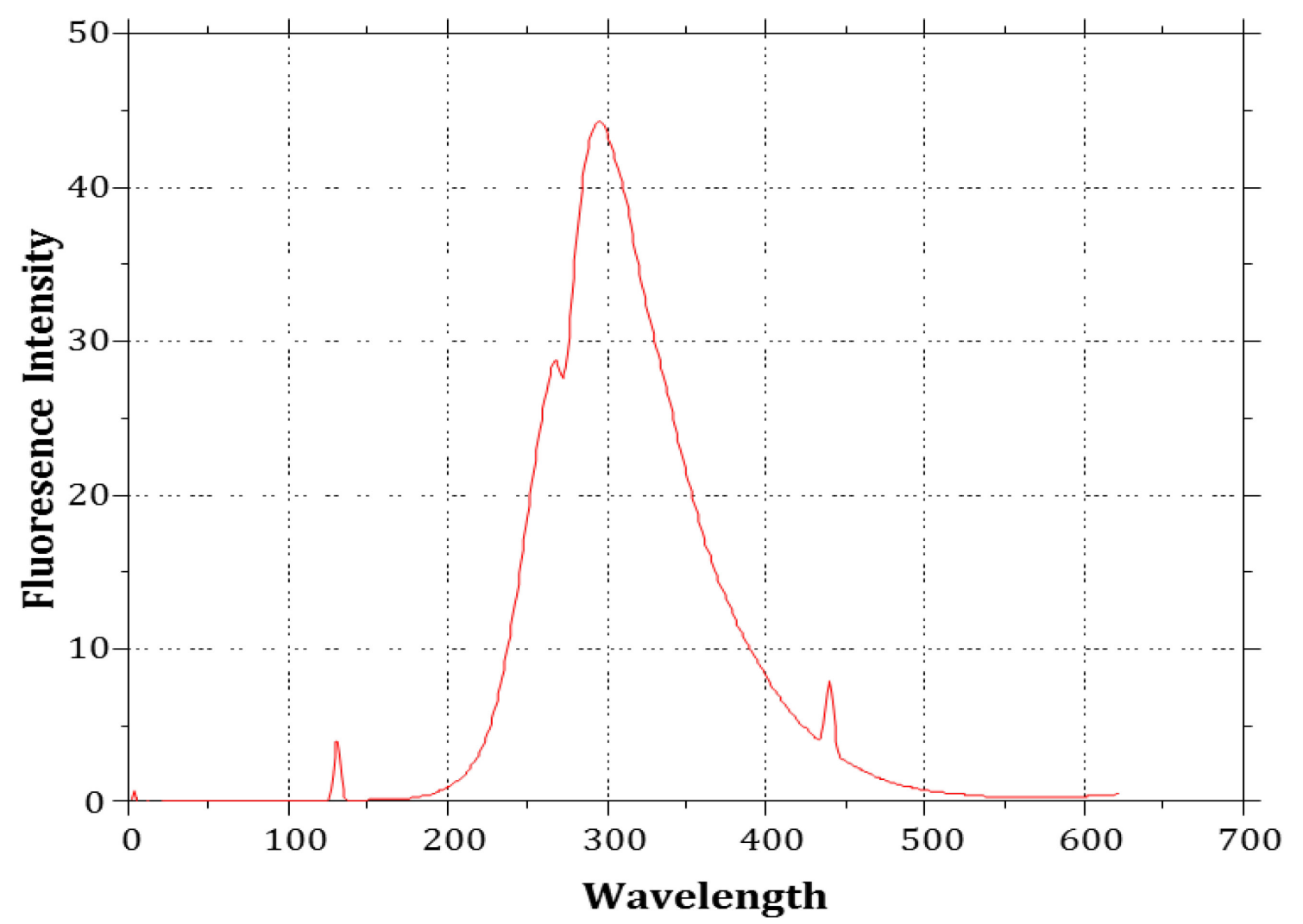

Figure 14. Fluorescence spectrum of PHE-3 


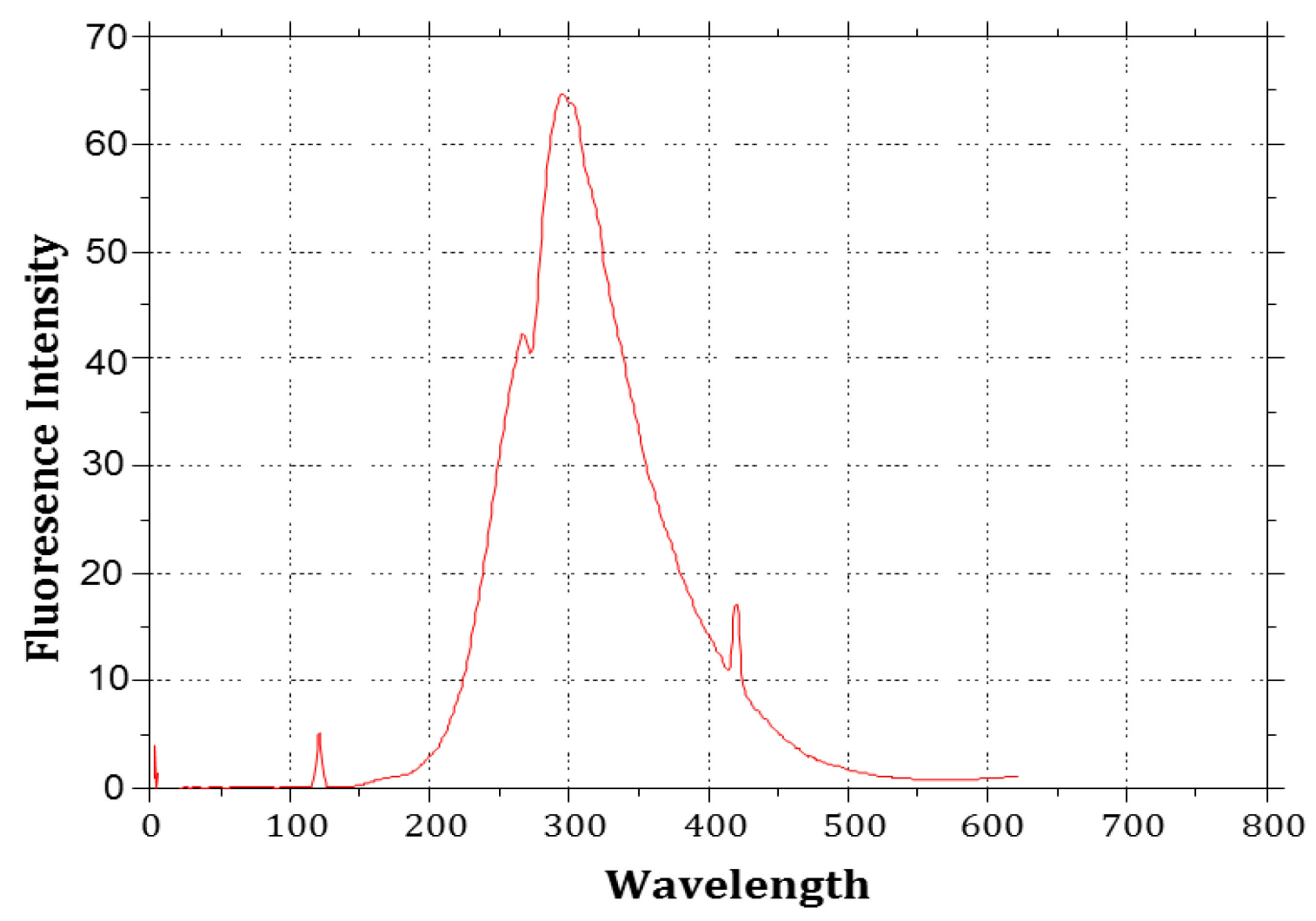

Figure 15. Fluorescence spectrum of PHE-6

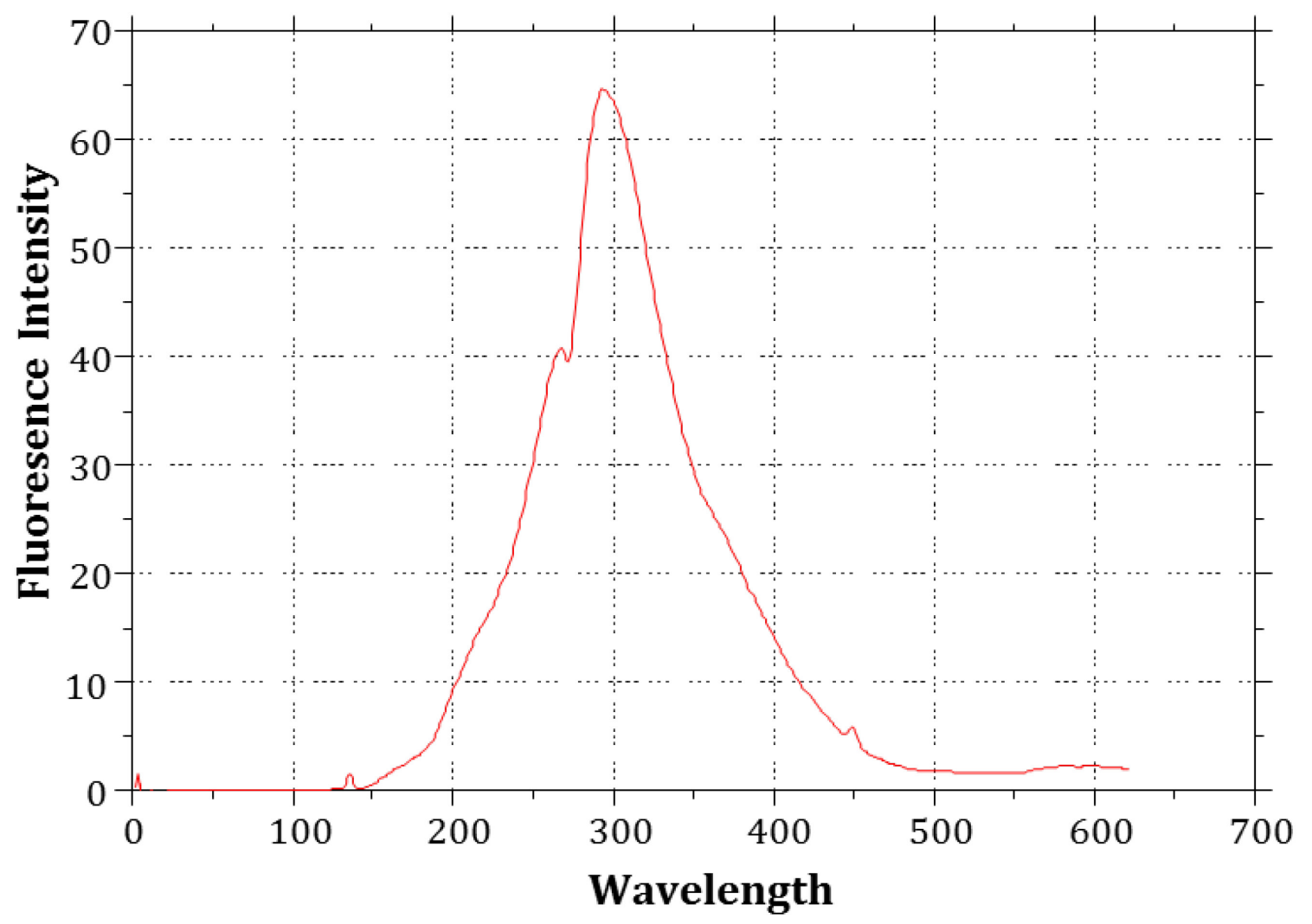

Figure 16. Fluorescence spectrum of PHE-7 


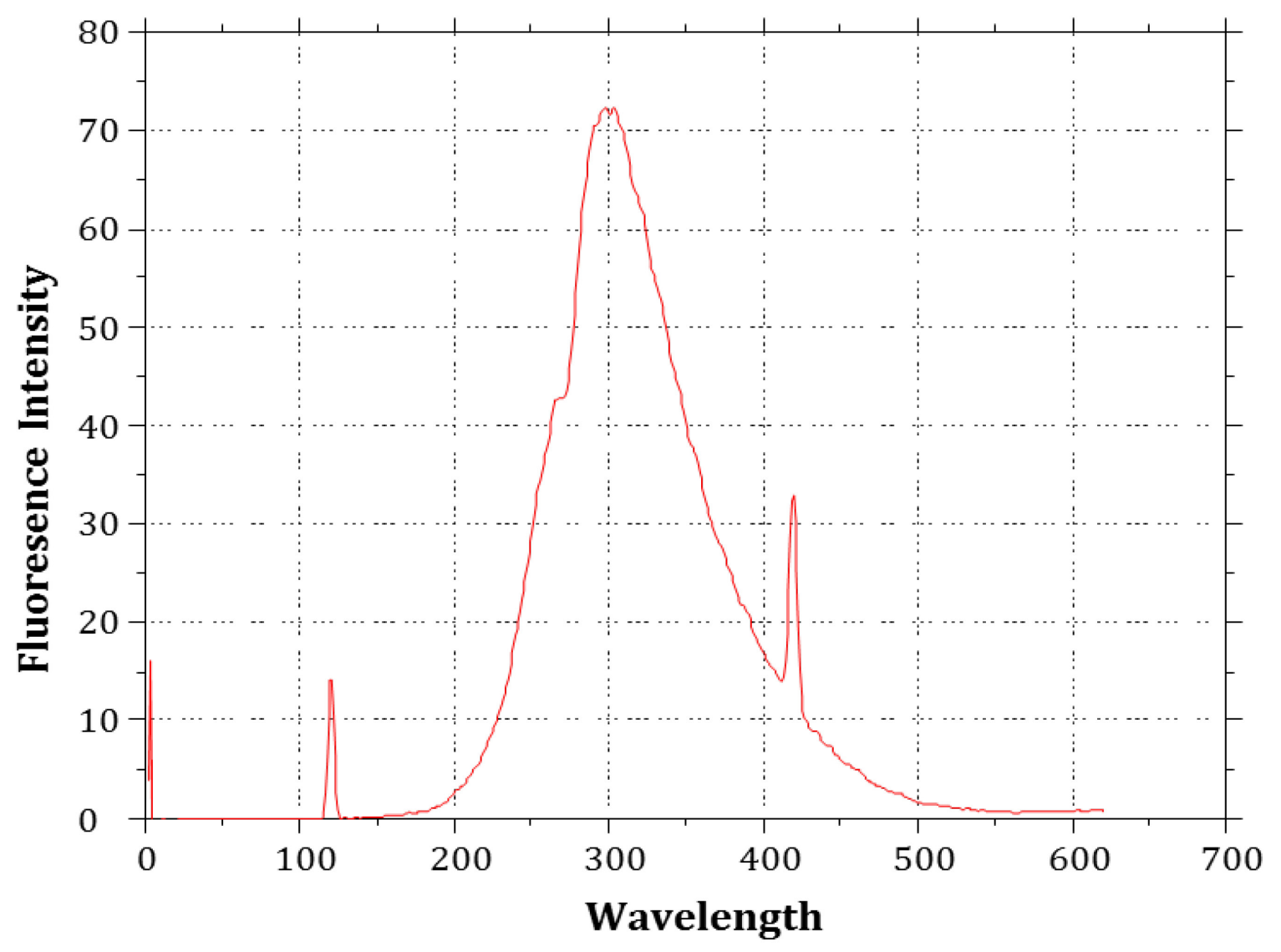

Figure 17. Fluorescence spectrum of PHE-9

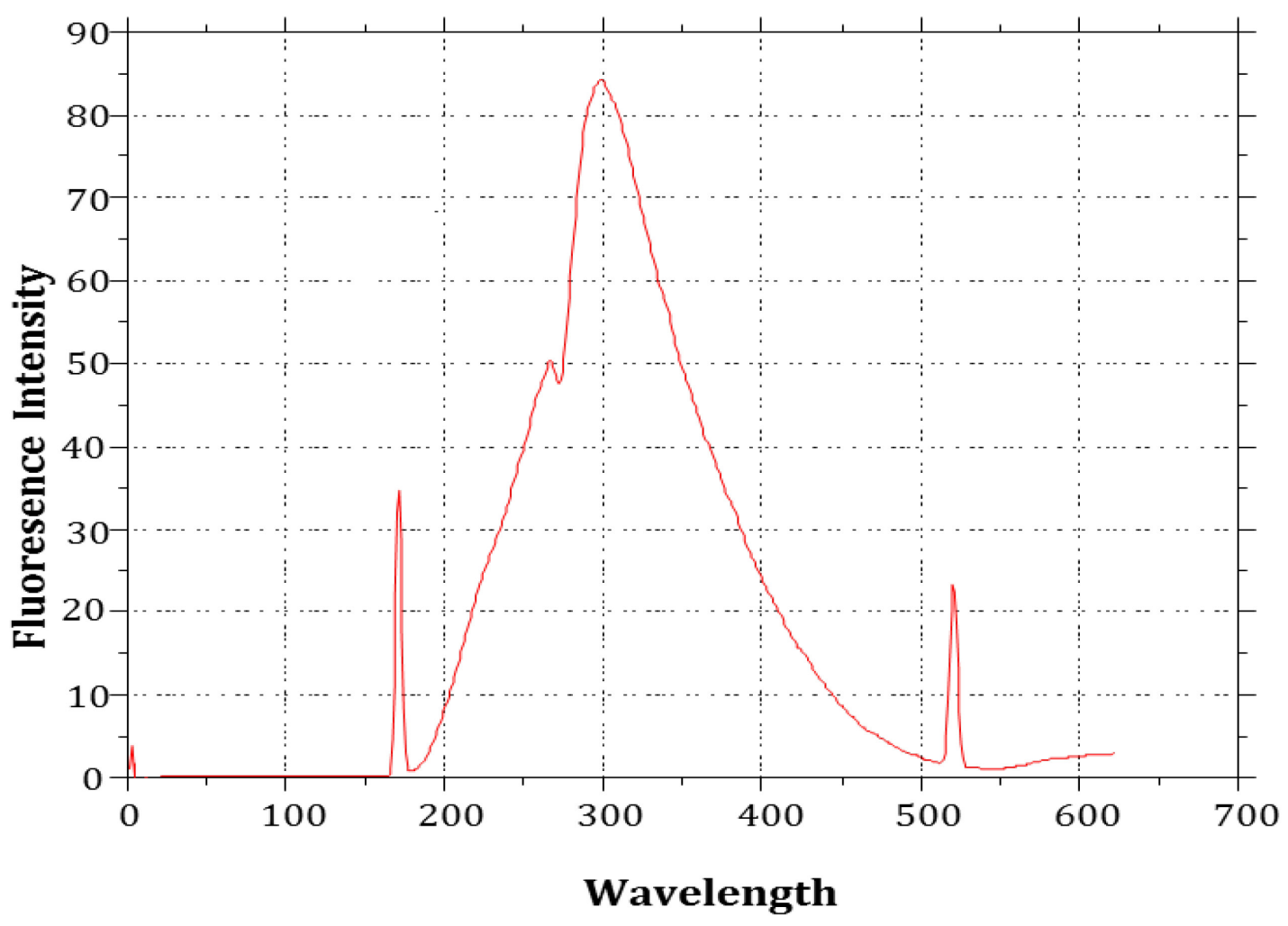

Figure 18. Fluorescence spectrum of PHE-10 


\section{Result and Discussions}

The resulting novel polyesters were obtained in good yields (80-95\%), with variety of colours. PHE-1 and PHE-3 showed light brown colour, PHE-2 and PHE-6 showed pink colour, PHE- 7 and PHE-8 were maroon PHE-9 and PHE-10 showed light yellow colour. All the novel polyesters were insoluble in benzene, chloroform, carbon tetrachloride and chlorobenzene but completely soluble in Ethyl acetate, DMF and DMSO and partly soluble in methanol, tetrahydrofuran, n-butanol, isopropyl alcohol and ether. The inherent viscosities of novel polyesters showed ranging between $0.402-0.709 \mathrm{dlg}^{-1}$. The intrinsic viscosity of polyesters were given this sequence $\quad$ PHE-3 $<$ PHE- $<$ PHE- $1<$ PHE- $8<$ PHE- $6<$ PHE- $4<$ PHE- $9<$ PHE- $10<$ PHE-5 $<$ PHE-7.The highest intrinsic viscosity was of PHE-7 due to molecule structure of polyester in which bisphenolA was used as diol. The thermal properties of different polyesters were evaluated by TGA at heating rate of $10^{\circ} \mathrm{C} / \mathrm{min}$ under a nitrogen atmosphere. TGA thermogram in figure (11) polyesters exhibited high thermal stability and lowest thermal stability was observed in figure (12). The high char yields of these polyesters could be ascribed to their high aromatic content. The series of polyesters showed higher thermal stability compared to the corresponding counterpart without coumarin moiety. Hence, the presence of heterocyclic compounds in novel polyesters proves the higher thermal stability of synthesized polyesters. The fluorescence spectrums of synthesized polyesters were observed. The presence of heterocycles and aromatic diols showed the highest intensity peak in figure (18) (PHE-10) and due to aliphatic diol the lowest intensity peak was observed in figure (14) (PHE-3).

\section{Conclusions}

The data indicates the creation of fluorescence and thermally stable polyesters by polycondensation of coumarin probe carboxylic acid and aliphatic-aromatic diols. The resulting polyesters show outstanding colours, solubility in organic solvents and good thermal stability. All the synthesized polyesters show excellent fluorescence which can be used in fluorescent probe, advanced bio imaging, ultrasensitive molecular diagnosis, novel light emitting nano devices, chemo sensors, biological imaging and drug delivery.

\section{Acknowledgement}

I wish to express my appreciation to the Principal, St. Xavier's College and Director, Xavier's Research Foundation (XRF), Ahmedabad for their support. I likewise express my gratitude to CSMCRI Bhavnagar and SAIF, Chandigarh, Punjab for investigation of the samples. I truly recognize UGC, New Delhi for the financial assistance throughout the work.

\section{References}

[1] B. Nottelet, V. Darcos, J. Coudane, Aliphatic polyesters for medical imaging and theranostic applications, Eur. J. Pharm. Biopharm. 97 (2015) 350-370.

[2] H. Chang at al., Photo-induced dynamic association of coumarin pendants within amphiphilic random copolymer micelles, Colloid and Polymer Science. 293(3) (2015) 823-831.

[3] J.Yu Son et al., Alkenylation of Phosphacoumarins via Aerobic Oxidative Heck Reactions and Their Synthetic Application to Fluorescent Benzophosphacoumarins, Org. Lett. 17(4) (2015) 908-911.

[4] J. Lee et al., Kinetics of UV Irradiation Induced Chain Scission and Cross-Linking of Coumarin-Containing Polyester Ultrathin Films Macromolecules. 47 (9) (2014) 2891-2898.

[5] M. Tasior et al., V-Shaped Bis-Coumarins: Synthesis and Optical Properties, J. Org. Chem. 79(18) (2014) 8723-8732.

[6] F. Zeng et al., Hyperbranched Polyester-Based Fluorescent Probe for Histone Deacetylase via Aggregation-Induced Emission, Biomacromolecules. 14(12) (2013) 4507-4514. 
[7] M.A. Harnessing, Sun's Energy with Quantum Dots Based Next Generation Solar Cell Nanomaterials. 3 (2013) 22-47.

[8] M. Cigáň et al., Spectral Properties of Substituted Coumarins in Solution and Polymer Matrices Jana Molecules. 17 (2012) 3259-3276.

[9] L.H. Zhang, T. Jian, L.B. Wan, Tetraphenylsilole-Based Conjugated Polymers: Synthesis, Optical Properties, and as Sensors for Explosive Compounds, Chem. Asian J. 7 (2012) 15831593.

[10] M.S.Al Salhi et al., Recent Advances in Conjugated Polymers for Light Emitting Devices, Int. J. Molec. Sci. 12 (2011) 2036-2054.

[11] Y. Wang, K. Pu, B. Liu, Anionic Conjugated Polymer with Aptamer-FunctionalizedSilica Nanoparticle for Label-Free Naked-Eye Detection of Lysozyme in Protein Mixtures, Langmuir. 26(12) (2010) 10025-10030.

[12] S. Thomas, G. Joly, T. Swager, Chemical Sensors Based on Amplifying Fluorescent Conjugated Polymers, Chem. Rev.107 (2007) 1339-1386.

[13] Y.Wang et al., Fluorescent ultrahigh-molecular-weight polyacrylamide probes for dynamic flowsystems: synthesis, conformational behavior and imaging, Macromol. Chem. Phys. 203(12) (2002) 1833-1843.

[14] H. Tanaka et al., Homogeneous fluorescent labeling of cationic polyacrylamides, J. Appl. Polym. Sci. 86(3) (2002) 672-675.

[15] K.C.Wang et al., Fluorescent polymer made from chemical modification of poly(styrene-comaleic anhydride), React. Funct. Polym. 52(3) (2002) 143-148.

[16] W.Y. Li, J.G. Xu, X.W. He, Determination of nucleic acids using rivanol as thefluorescent probe in the presence of SDS, Anal. Lett. 33(15) (2000) 3183-3194.

[17] [I. Soutar et al., Fluorescence studies of the dynamic behavior of poly(dimethylacrylamide) and its complex with poly(methacrylic acid) in dilute solution Macromolecules. 29(3) (1996) 918-924.

[18] J.R. Lakowicz, Principles of Fluorescence Spectroscopy, Plenum Press, New York, 1999.

[19] J.S. Yang, T.M. Swager, Porous Shape Persistent Fluorescent Polymer Films: An Approach to TNT Sensory Material, J. Am. Chem. Soc. 120(21) (1998) 5321-5322.

[20] M.A. Winnik et al., Synthesis and characterizationof pyrene-labeled poly(ethylenimine) Macromolecules. 31(20) (1998) 6855-6864.

[21] H.L. Chen, H. Morawetz, Fluorometric study of the equilibrium and kinetics ofpoly(acrylic acid) association with polyoxyethylene or poly(vinyl pyrrolidone), Eur. Polym. J. 19(10/11) (1983) 923-928.

[22] N.J. Turro, K.S Arora, Pyrene as a photophysical probe for intermolecular interactions of water-soluble polymers in dilute solutions, Polymer. 27 (1986) 783-796. 